\title{
AÇÃO DE GIBERELINA E AUXINA EM DIFERENTES REGIÕES DO CACHO DE BANANAS EM DESENVOLVIMENTO*
}

\author{
VLADIMIR R. SAMPAIO** \\ PAULO R.C. CASTRO*** \\ DÉCIO BARBIN ****
}

\begin{abstract}
RESUMO
Estudaram-se os efeitos da apiicação de diferentes concentrações de giberelinas e do ácido 2-hidroximetil 4-clorofenoxiacético em cachos de bananas da cultivar 'Nanicão'. As pulverizações dos produtos isolados ou em combinação, foram efetuadas no cacho in teiro, ou então somente nas duas pencas terminais. As aplicações foram realizadas por ocasião do surgimento da última penca nos cachos.

Os tratamentos não alteraram os seguintes parâmetros mensurados: comprimento do fruco médio do cacho, comprimento do fruto da penúltima penca e do peso dos frutos da penúltima e última pencas.
\end{abstract}

\section{INTRODUÇÃO}

Apesar de poucos trabalhos terem sido realizados sobre o processo de desenvolvimento dos frutos da bananeira, LUCKWILL (1957) considera que dois.são os estímulos principais ao seu desenvolvimento. Observou que um necessário impulso inicial seria proporcionado por citocininas produzidas no endosperma e o crescimento subseqüente seria provocado pelas auxinas responsáveis pelo aumento nas dimensões celulares. Este esquema oferece uma explicação plausivel ao desenvolvimento de frutos do morangueiro e outros nos quais a aplicação de auxina somente estimula o crescimento se ocorrer uma limitação no desenvolvimento das sementes.

Frutos nos quais um al to nível de partenocarpia pode ser induzido pelo tratamento com auxina, como no caso do tomateiro, são aqueles nos quais o crescimento do ovário, após o florescimento, ocorre primeiramente por aumento nas dimensões celulares e subseqüentemente por divisões celulares.

Em frutos da bananeira, citocinina e auxina (provavelmente o ácido indolacético) têm sido encontradas (NICHOLS, 1958). Auxinas aplicadas externamente, em pasta de lanolina, induzem um grau moderado de partenocarpia, em frutos de cultivares com sementes não polinizados e estimulam o crescimento da polpa,em cultivares aspérmicas (SIMMONDS, 1953).

Em sua reação à aplicação de auxinas, as cultivares de bananeiras com sementes parecem ser intermediárias entre a reação do morangueiro e do tomateiro, implicando so-

* Entregue para publicação em 29/12/1975.

* Departamento de Agricultura e Horticultura - E.S.A. "Luiz de Queiroz" - USP.

** Departamento de Botânica - E.S.A. "Luiz de Queiroz" - USP.

*** Departamento de Matemática e Estatística - E.S.A. "Luiz de Queiroz" - USP. 
mente numa dependência parcial às sementes, que seriam uma fonte inicial dè citocininas.

SIMMONDS (1960) estudou os efeitos da aplicação de auxinas e de anti-auxinas, em pasta de lanolina. nos frutos novos da bananeira. Observou que as auxinas estimulam a formação da polpa comestivel nas cultivares com sementes e aspérmicas; sendo que induzem ainda graus variáveis de esterilidade da semente. A cumarina estimulou a partenocarpia e promoveu esterilidade da semente; sendo que a tiouréia inibiu a partenocarpia.

Estudo da relação entre o tamanho do fruto maduro e o conteúdo de sementes, indicou que o desenvolvimento das sementes estimulou a formação da polpa; sendo que a intensidade do estímulo é proporcional ao nível de partenocarpia.

$O$ presente trabalho foi realizado com a finalidade de se verificar o efeito da aplicação do ácido giberélico e do ácido 2-hidroximetil 4-clorofenoxiacético, em diferentes regiões do cacho de bananas e no comprimento e no peso dos frutos.

\section{MATERIAIS E METODOS}

O ensaio foi realizado no Setor de Horticultura da E.S.A. "Luiz de Queiroz", em Piracicaba, nos anos de 1974 e 1975 em bananal da cultivar 'Nanicão'. O bananal com 2 anos de idade estava localizado em solo classificado como Latossol, série Luiz de Queiroz.

Tratos culturais - Na condução do bananal, foi deixado sempre um portador e um seguidor, por touceira, de maneira a manter o espaçamento inicial de $2,50 \times 1,80 \mathrm{~m}$. $O$ desbaste dos excedentes e escolha dos seguidores para a realização do ensaio foi realizado em julho de 1974, procurando-se uniformidade para a próxima produção.

$\mathrm{Na}$ continuidade do programa de adubação, a plantação recebeu uma aplicação de sulfato de amônio (300 g por cova) em 14/08/74. Adubações fosfatadas e potássicas tinha sido feitas anteriormente. Irrigações por gravidade, foram feitas a partir de $12 / 8 / 74$.

Para manutenção da sanidade do bananal, foi executado a 31/7/74, tratamento das touceiras com "Aldrim", visando controle da broca. Não foi necessário pulverizar contra a cercosporiose, cuja ocorrência foi mínima durante o transcorrer do ensaio.

Execução do experimento - Os cachos a serem tratados, surgiram de dezembro de 1974 a maio de 1975, surgindo em maior número nos meses de fevereiro e março.

A data de saída das inflorescências, era anotada através de vistorias semanais. As pulverizações foram executadas em cachos sem umidade externa, sendo os mesmos protegidos após a aplicação durante 48 horas, por sacos plásticos, a fim de evitar lavagem do produto utilizado. Os cachos foram colhidos 90 dias após as emergências, e suas principais características mensuradas e pesadas.

Foram utilizados 2 produtos: "Gibrel" da Merck Chemical Division com $2 \%$ de giberelato de potássio $\left(\mathrm{KGA}_{3}\right)$ e o "Trylone" da Rhône-Poulenc com ácido 2-hidroximetil 4-clorofenoxiacético (2,4-CPA). 
As aplicações foram efetuadas, quando do surgimento da última penca, sendo utilizadas dosagens variadas. As pulverizações foram feitas ou no cacho todo, ou somente nas duas pencas terminais.

Delineamento experimental - Adotou-se o delineamento experimental denominado Blocos ao Acaso, com 12 tratamentos e 3 repetições. Cada parcela era constituída de 2 plantas.

Os tratamentos foram os seguintes:

1 - Controle;

2 - Cacho inteiro - $\mathrm{KGA}_{3} 50 \mathrm{ppm}$;

3 - Cacho inteiro - $\mathrm{KGA}_{3} 100 \mathrm{ppm}$;

4 - Cacho inteiro - $\mathrm{KGA}_{3} 200 \mathrm{ppm}$;

5 - Cacho inteiro - 2,4-CPA $25 \mathrm{ppm}$;

6 - Cacho inteiro - 2,4-CPA 50 ppm:

7 - Cacho inteiro - KGA $100 \mathrm{ppm}+2,4-\mathrm{CPA} 25 \mathrm{ppm}$;

$8-2$ pencas - $\mathrm{KGA}_{3} 50 \mathrm{ppm}$;

$9-2$ pencas - $\mathrm{KGA}_{3} 100 \mathrm{ppm}$;

$10-2$ pencas - KGA $200 \mathrm{ppm}$;

11 - 2 pencas $-2,4-\mathrm{CPA} 25 \mathrm{ppm}$;

12 - 2 pencas - 2,4-CPA 50 ppm;

\section{RESULTADOS E DISCUSSÃo}

Foram analisados os resultados referentes ao comprimento do fruto externo médio do cacho e ao comprimento do fruto da penúltima penca expressa em porcentagem em relação ao fruto médio do cacho, e aos pesos médios dos frutos da última e penúltima pencas expressos em porcentagem em relação ao peso do fruto médio. Os resultados médios para os tratamentos estão representados no quadro 1 . 


\begin{tabular}{ccccc}
\hline Tratamentos & $\begin{array}{c}\text { Comp. em cm } \\
\text { do fruto } \\
\text { médio }\end{array}$ & $\begin{array}{c}\text { Comp. do fruto } \\
\text { da penúltima } \\
\text { penca em \% }\end{array}$ & $\begin{array}{c}\text { Peso em g do fruto } \\
\text { da penúltima } \\
\text { penca em } \%\end{array}$ & $\begin{array}{c}\text { Peso em g do fruto } \\
\text { da última } \\
\text { penca em \% }\end{array}$ \\
\hline 1 & 17,3 & 90,9 & 90,7 & 78,3 \\
2 & 17,1 & 92,4 & 90,2 & 79,6 \\
3 & 16,6 & 91,0 & 88,8 & 77,3 \\
4 & 17,5 & 88,9 & 90,7 & 78,3 \\
5 & 17,0 & 90,8 & 90,0 & 80,0 \\
6 & 16,4 & 91,7 & 87,0 & 68,9 \\
7 & 16,7 & 90,3 & 94,8 & 76,9 \\
8 & 16,8 & 90,8 & 89,0 & 78,9 \\
9 & 17,2 & 89,6 & 87,1 & 76,8 \\
10 & 16,2 & 95,6 & 94,1 & 79,9 \\
11 & 17,6 & 90,4 & 86,6 & 75,3 \\
12 & 16,6 & 92,4 & 89,1 & 80,5
\end{tabular}

QUADRO 1 - Resultados médios obtidos para os vários tratamentos.

Os resultádos anteriores foram analisados estatisticamente e resultaram nos valores expressos no quadro 2 .

\begin{tabular}{|c|c|c|c|c|c|}
\hline \multirow[b]{2}{*}{$\begin{array}{l}\text { Causa de } \\
\text { Variação }\end{array}$} & \multirow[b]{2}{*}{ G.L. } & \multicolumn{4}{|c|}{ Quadrado Médio } \\
\hline & & $\begin{array}{l}\text { Comp. em } \mathrm{cm} \\
\text { do fruto } \\
\text { médio }\end{array}$ & $\begin{array}{c}\text { Comp. do fruto } \\
\text { da penúltima } \\
\text { penca em } \%\end{array}$ & $\begin{array}{c}\text { Peso do fruto da } \\
\text { penúltima } \\
\text { penca em } \%\end{array}$ & $\begin{array}{l}\text { Peso do fruto da } \\
\text { penúltima } \\
\text { penca em } \%\end{array}$ \\
\hline $\begin{array}{l}\text { Reg. do } \\
\text { cacho (R) } \\
\text { Dosagem: }\end{array}$ & 1 & 0,0013 & 4,8803 & 0,2430 & 16,1333 \\
\hline (D) & 4 & 0,5072 & 4,6942 & 21,1313 & 20,6180 \\
\hline Int. $(\mathrm{R} \times \mathrm{D})$ & 4 & 0,8922 & 17,1628 & 11,6797 & $55,7400 *$ \\
\hline $\begin{array}{l}\text { (Fatorial) } \\
\text { Fat. nos }\end{array}$ & (9) & & & & \\
\hline $\begin{array}{l}\text { Outros } \\
\text { Entre }\end{array}$ & 1 & 0,0569 & 2,6889 & $60,4361 *$ & 0,0269 \\
\hline Outros & 1 & 0,4267 & 0,6017 & 24,8067 & 2,9400 \\
\hline (Tratamento) & (11) & 0,5529 & 8,6908 & 20,1520 & 29.5029 \\
\hline Blocos & 2 & 2,0753 & 1,7436 & 19,7027 & 7,2586 \\
\hline Resíduo & 22 & 1,2810 & 7,7103 & 9,4613 & 14,7083 \\
\hline Total & 35 & C.V. : $6,69 \%$ & C.V. : $3,04 \%$ & C.V. : $3,42 \%$ & C.V. : $4,94 \%$ \\
\hline
\end{tabular}

QUADRO 2 - Resultados das análises estatísticas dos valores cujas médias estão no Quadro 1 
Pelos valores obtidos através da análise, verifica-se a ineficiência do emprego da giberelina e do ácido 2-hidroximetil 4-clorofenoxiacético nas condições estudadas. Dos dois únicos resultados significativos somente aquele referente a interação $(R \times D)$ para $o$ peso do fruto da última penca em porcentagem, poderia ter interesse. Assim foi efetuado o desdobramento que vem a seguir.

$\begin{array}{lrl}\text { Causa da Variação } & \text { G.L. } & \\ \text { Entre dosagens d R } & 4 & 62,3523 * \\ \text { Entre dosagens d } R_{2} & 4 & 14,0057 \\ \text { Resíduo } & 22 & 14,7083\end{array}$

Calculada a D.M.S., cujo valor encontrado foi de 9,30 , tornou-se possivel comparar as médias dos tratamentos dentro da Região 1 (cacho inteiro).

$\begin{array}{lr}\mathrm{KGA}_{3} & 50-79,60 \\ \mathrm{KGA}_{3} & 100-77,33 \\ \mathrm{KGA}_{3} & 200-78,27 \\ 2,4-\mathrm{CPA} & 25-80,03 \\ 2,4-\mathrm{CPA} & 50-68,90\end{array}$

Donde encontra-se que o tratamento 2,4-CPA a $50 \mathrm{ppm}$ diferiu significativamente ao nivel de $5 \%$ de probabilidade dos tratamentos 2,4-CPA $25, \mathrm{KGA}_{3} 50$ e $\mathrm{KGA}_{3} 200$, quando dos tratamentos aplicados ao cacho inteiro. Essa aparente fitotoxicidade do produto, é de dificil explicação pelo fato desse efeito prejudicial não ter ocorrido, quando tratadas foram somente as pencas basais.

\section{CONCLUSÕES}

O presente experimento permitiu as seguin tes conclusões:

1 - A aplicação de giberelina nas dosagens de 50, 100 e 200 ppm, no cacho inteiro de bananas ou tão somente nas duas pencas terminais, não ocasionou alteração alguma, tanto para elongamento como para peso dos frutos.

2 - A aplicação do ácido 2-hidroximetil 4-clorofenoxiacético nas dosagens de 25 e 50 ppm também foi ineficiente para os parâmetros mensurados. A dosagem de 50 ppm, aparentemente mostrou certa fitoxicidade.

3 - A combinação da giberelina e do ácido 2-hidroximetil 4-clorofenoxiacético nas dosagens respectivas de 100 e 25 ppm, também não mostrou resultados significativos. 


\section{ACTION OF GIBBERELLIN AND AUXIN IN DIFFERENT REGIONS OF THE BUNCH OF DEVELOPING BANANAS}

We studied the effects of gibberellic acid and 2-hydroxymethyl-4-chlorophenoxyacetic acid on bunches of bananas cultivar 'Nanicão'. Applications of several concentrations of the chemicals isolately or in combination, were realized in the totai bunch or in the last two hands (clusters) of the bunch. The sprays were applied in the moment of development of the last hand of the bunch.

The treatments do not change the following parameters: length of the medium fruit (finger) of the bunch, length of the medium fruit of the next to last hand, and the weight of fruits of the last two hands of the bunch.

\section{LITERATURA CITADA}

LUCKWILL, L.C., 1957. Hormonal aspects of fruit development in higher plants. Symp. Soc. Exp. Biol., 11.63-85.

NICHOLS, R., 1958. A possible source of error in the chemical detection of indolylacetic acid in plants. Nature, $181919-920$.

SIMMONDS, N.W., 1953. The development of the banana fruit. J. Exp. Bot., 4:87-105.

SIMMONDS, N.W., 1960. Experiments on banana fruit development. Ann. Bot., 24:212-222. 